\title{
Information and Communication Technology (ICT) as a Tool of Differentiated Instruction: An Informative Intervention and a Comparative Study on Educators' Views and Extent of ICT Use
}

\author{
Zoi Karatza
}

\begin{abstract}
The differentiated instruction / differentiated classroom has been the subject of numerous studies and discussions regarding its application in today's classrooms. Consequently, the differentiation of the teaching approach would not be unrelated to essential characteristic of our generation, namely the use of technology and its tools in any everyday activity. Nowadays, it is widely realized and accepted that both of the concepts of differentiated instruction and the educational use of Information and Communication Technology (ICT) are necessary for the modern educational practice and for that reason the present dissertation focuses on linking these two issues. The purpose of this research is to study educators' views on the use of ICT to differentiate their instruction and explore their extent of ICT use.
\end{abstract}

Index Terms-Differentiated instruction, educational technology, ICT, learning style, animated video.

\section{INTRODUCTION}

In any class, students differ in many characteristics such as: the individual development rates, the educational backgrounds, the motivation, the interests, the prior knowledge, the skills and the strategies for acquiring knowledge and the level of readiness of each one. All these factors create diversity in the classroom, which leads to the need for an education that includes all the students.

However, this is not happening, at least not to a sufficient degree, because of the traditional and undifferentiated didactic approaches, which do not contribute to "building knowledge" for all the students in a mixed ability class [1]. It has been emphasized that "education and social justice can only be met if teachers find the way to correspond to the diversity of their students through differentiated instruction. Someone can state that equity is the opportunity all groups of students have in a mixed ability classroom, in achieving the maximum concerning the goals of the curriculum, according to the personal abilities and competences of each student ensuring equal access to knowledge" [2].

Differentiated instruction seeks to bring changes in the learning process so that it responds to a wide range of differences in learners' readiness, interests and learning styles [3], [4]. At the same time, it has the potential to reconstruct the traditional classroom, combating the exclusion of

Manuscript received December 19, 2017; revised February 29, 2018.

Zoi Karatza is with the American Community Schools of Athens (ACS Athens), University of Athens, University of Thessaly and Piraeus University of Applied Sciences, Greece (e-mail: zoikar@ecd.uoa.gr, zoikaratza93@gmail.com). individuals with particular characteristics and also include all students with a variety of skills, interests and learning profiles. In this way, teaching and learning are converted into processes that motivate and create expectations for all students [5], [6]. Differentiation is not a teaching recipe [7] but an innovative way of teaching and learning. There are different forms, categories, techniques and strategies that can be used by a teacher, taking into account the profile, the interests, the needs, the skills, the abilities and the cultural background of his/her students [8]. In order for teachers to achieve differentiation, they should use the available tools that support this process. For the past two decades, technological tools have received great attention since it has been proved that they can contribute to improving learning experiences, as long as they are integrated into a proper educational framework. Information and Communication Technology (ICT) is considered as a key tool for supporting teachers who adopt differentiated instruction, since it gives students with different learning profiles the opportunity to work at the same level, at the same time and through possible peer interaction.

Plenty of research supports that ICT, being used appropriately and in the right context in teaching practice, increases students' motivation, encourages active participation and collaborative learning and positively affects the learning process [9]-[15]. The use of ICT tools can actually contribute to differentiation as they are able to promote students' active role, provide opportunities for changing and modifying teaching and learning approaches. Thus, they promote a positive learning environment as long as students' motivation and interest persist.

\section{RESEARCH METHODOLOGY}

The current research lasted approximately seven months and the vast majority of the participants worked at the American Community Schools of Athens (ACS Athens). The research began with the review and study of the relevant literature, the construction of the tools and the production of the digital material. A questionnaire was created and shared for collecting data and an animated video was designed, through which an informative intervention was delivered to a group of teachers. Finally, the research was completed by the statistical analysis of the questionnaire data along with the information which was collected by the informative intervention. These were used for the design and planning of two proposed teaching scenarios using ICT tools to differentiate the learning process. 


\section{LITERATURE REVIEW}

\section{A. Differentiated Instruction}

Differentiated instruction is essentially the practical aspect of a differentiated pedagogical philosophy. It is an organized and flexible way of adapting teaching and learning so that it responds to students' performance levels, but also it allows them to realize and fulfill their potential. It constitutes the modern teaching proposal that has the potential to rebuild the traditional classroom by including all students with a variety of competencies, interests and learning profiles.

It has now been widely accepted that differentiated instruction is a fundamental component of many theories and practices related to effective instruction. More precisely, the foundations of differentiation is linked to the constructivist theories, the modern heterogeneity of classes, the risk of the basing instruction only on the "average" or "typical" student, the research on human brain functions and the exploration of individual learning styles as well as the theories of multiple intelligences [16]. Differentiation can be achieved if educators follow the basic principles of its philosophy. Among them, the most important are: 1. Flexibility, 2. Learning experiences are based on each student's level of readiness, interests and learning styles, 3 . Focus and emphasis on the potential and the strengths of each student, 4. Acceptance and respect of diversity and design educational activities based on this principle, 5. Teaching approach is constantly being modified and shaped by the students.

Then, educators can differentiate their instruction through three ways: 1) content, 2) process and 3) product. The content is "what students learn, the materials, or even the mechanisms through which learning is achieved" [17]. Moreover, the content consists of the knowledge, the concepts and the skills which are required for students to learn. It also includes what the teacher plans for his/her students to learn and how students achieve access to this content. Consequently, the differentiation by content refers to changes and adjustments of what the learner aims to learn and includes the various ways of delivery such as videos, texts, lectures, or audio. In this way, the multimodality of the content delivery enables students to choose their content and its form focusing on their interests and preferences. Among the most effective strategies for differentiated instruction by content are: shrinking curriculum, extending time limits, using audiovisual materials and using ICT.

The process is how students give meaning to the content presented, how they understand and acquire key facts, concepts and skills. The process consists of the strategies and methods that shape instruction and refers to the many activities that vary in response to students' interests and preferences for learning. In other words, it refers to the way the student has access to the material. Therefore, the process can be differentiated by increasing or decreasing the degree of complexity of activities, by engaging students in a process of critical and creative thinking, adding more ways to achieve the objectives of the curriculum [18] and extending the time to do so. Strategies commonly used to differentiate the process include: developing personal daily lists, extending time limits, modifying the teaching rate, teaching in smaller groups, using conceptual maps, using tiered activities, option tables, web pages, course layout and collaborative projects.

The differentiation by product refers to how students will show what they have learned and understood in terms of the knowledge and skills taught. In a differentiated classroom, the product is considered as one of the tools that educators use to assess the progress based on the content goals. It has also been argued that the differentiation by product refers to how each student demonstrates what he/she has learned and understood, what he/she can do after a period of study. It also depends on how students choose to show what they have achieved based on their preferences, learning styles and level of readiness [19]. One of the most widespread strategies to differentiate by product is to offer students the opportunity to choose their work or the way they will be evaluated. Other ways to differentiate by product are: adopting alternative forms of evaluation, alternative or modified assignments and independent projects.

\section{B. The Impact of ICT in Education}

There are many research results which support and prove the educational value of ICT. For preschool children, the results of specific research converge on the fact that computers can be used as a tool that contribute to their personal, socio-emotional and cognitive development [20]-[24]. In addition, computers increase independence and children's sense of control over their learning, which increases motivation and self-confidence [25]. Especially, it has been supported that teaching using new technologies offers and creates new motivations for learning [26]-[28]. Additionally, there is evidence for the positive impact of digital applications to the learning development of preschool children [29], [30]. Based on the theories of Constructivism and the Zone of Proximal Development, researchers have argued that digital applications offer opportunities for interaction between the pedagogical groups, while underlying the distinctive role of the adult (educator), a combination that contributes to the successful cognitive development of children. Other results support that the use of new technologies in class contributes to empowering students to be more effective at school and to improving their self-confidence and self-esteem. [31], [32].

Researchers have argued educators who use ICT in their instruction, offer opportunities for active and independent learning, which leads to an increase in students' interest. Also, it has been stated that ICT can act as a facilitator of active learning and higher order thinking [33]. However, the proper educational use of technology has both quantitative and qualitative positive results in comparison with the traditional teaching methods. In other words, there is qualitative improvement in student work and academic performance.

One more advantage of using ICT in education is the collaborative learning processes, which have been emphasized to such extent that two new concepts have been added to the bibliography: "Computer-supported collaborative learning" and "Computer-supported collaborative work". This, in turn, leads to social interaction and communication among the students as well as between students and educators. It has also a positive impact on the development of dialogue, the exchange of ideas and negotiation among students and it improves the relationships between children coming from different cultural 
environments by increasing the acceptance and understanding [34], [35]. Therefore, we might conclude that ICT can be used as a tool to differentiate curriculum and provide opportunities to adapt the learning content to the needs and abilities of each learner.

\section{ICT as a Tool of Differentiated Instruction}

Technological tools are characterized by interactivity and attractiveness and are able to support the educators who attempt to adapt their instruction to students' learning styles, interests and level of readiness. New technologies support accessibility, accommodation and modification of content, the materials and the educational learning environments. They also offer an almost limitless number of ways and means of shaping content, learning activities and processes to identify and evaluate the achievement of the goals they set. ICT encourages and facilitates the learning pace and personal choices of the students due to the multi-sensor and multimedia approaches. Knowledge is presented in many stimuli (visual, acoustic and linguistic) resulting in responding to more learning profiles since more senses (vision, hearing, touch) are stimulated. Multimedia indeed is a main feature of ICT. In this respect, students have reported that they learn better, understanding more difficult concepts with greater ease and retaining the subject matter when multimedia presentations are used. Moreover, multimedia offers students opportunities for "practical" learning, better concentration, specific feedback and increased levels of understanding [36]. In addition to multimedia, other important features of ICT, which make them suitable for supporting differentiated instruction, are: privacy, collaborative and communication skills, organization, support of learning styles and multisensory learning. A learning environment that adopts differentiated instruction can also use the tools offered by ICT and educators can have the opportunity to differentiate the learning process in all three dimensions (content, process and product).

As mentioned above, differentiation by content can be achieved in a variety of ways, but the two main include (a) using different content to teach the same subject to students with different needs and b) enhance / expand / adapt the available content so that it is accessible to all learners. Regarding the first strategy that educators find a new different content, the World Wide Web now provides a wide range of available materials for teachers and students. This range includes digital books, simulations, visualizations, applications, illustrations, graphs, scientific videos, audio and video files, animations and more that can present and explain concepts of the learning content. Students are now able to interact easily and directly with the educational material in many different ways and with different media that best responds to their learning styles. The most important is that educators are provided with rich resources, often with a different level of complexity. Regarding the second strategy, educators should extend and/or adapt the existing content. ICT can offer the tools so that the same content is accessible to all students. For example, text-based learning may either not meet the needs, or not support the profile of some students, however it may be accessible to everyone with the support of technology. Specifically, some of the ICT tools that can adapt content to students' needs are the following: conceptual maps (Kidspiration, Inspiration, Bubbl.us, Cmap кaı Webspiration) screen reader software NVDA (NonVisual Desktop Access), digital textbooks, EBooks, audiobooks and word processing, such as Microsoft Word.

The same happens respectively to differentiation by process since educators can focus on students' readiness, their interests and their learning profiles. ICT offers educators and students a variety of different ways to explore, research, study and evaluate both the concepts to be taught and the learning objectives. All these can be achieved because ICT tools are able to differentiate the processing, manipulating and recording information, but also the time each student needs for these functions, and adapt it accordingly. Regarding the process, manipulation and record of information, ICT can support the student not only individually but also as a group as it can enhance teamwork, and thus offering flexibility in the classroom. For example, the use of a laptop or other device with a word processor will help a student with a dysgraphia, who faces difficulties in keeping notes during the lesson because of his difficulty in writing. Also, open-source software, collaborative learning environments and in general all the interactive tools of the Web.2. create an open learning environment by motivating students. Ebooks, social networks, Forums, Youtube, online magazines, graphic organizers, and mind mapping enables students to learn based on their learning styles.

Specifically, some of the ICT tools which can adapt content to students' needs are the following: conceptual maps (Kidspiration, Inspiration, Bubbl.us, Cmap каı Webspiration) screen reader software NVDA (NonVisual Desktop Access), digital textbooks, eBooks, audiobooks and word processor, such as Microsoft Word. In addition, educators may use web-quests like Internet Scavenger Hunts, simulations, Wikis and e-learning platforms such as Moodle to enrich, extend and personalize their instruction. Another way of differentiation by process is to extend the learning duration. Educators mustn't forget that there are students in their classrooms with learning difficulties or students who need more time to process new information. ICT enables students to access the lesson's material outside of school. Namely, e-learning platforms, such as Moodle and Blackboard allow educators to extend the accessibility to learning content beyond the time of actual instruction. These platforms can also support on-line lessons thanks to asynchronous e-learning, which eliminates physical obstacles and saves time, thus giving opportunities for flexibility in time, space and learning pace.

In turn, differentiation by product means choosing a different way, by which each student will show everything he/she has acquired and understood in terms of the knowledge and skills taught. Consequently, educators should allow and accept the various ways by which each student chooses to express the acquisition of the new knowledge. A first way of differentiation by product using ICT is to provide the learner with the opportunity to demonstrate their learning with Web 2.0 tools. Specifically, Web 2.0 tools such as Podcasts, Blogs, Wikis, digital narrative applications, shared /collaborative presentations (eg Prezi), Youtube and social networks enable students to show what they have learned through creative and collaborative projects. Therefore, ICT tools can contribute to 
the enhancement of students' creativity and skill development [37]. A second way for educators to differentiate their instruction by product using ICT tools is to give students the opportunity to demonstrate their understanding through multimedia. Multimedia supports students who face difficulties in organizing and expressing their thoughts by providing them with different ways of expressing their writing, while simultaneously respecting individuals' strengths and weaknesses. Such tools are: digital posters (i.e. Gloster platform), digital storytelling (i.e. Storybird, Storyboard) and Voicethread. adapt the learning content to the needs and abilities of each learner.

\section{Learning Styles}

The term "learning style" is used in literature to describe the differences in the preferential way of learning among individuals. Since it has been found that learning style affects the learning process, researchers have shown an increasing interest in it, thus leading to the existence of diverse definitions of this term. However, all definitions agree that learning style refers to the way the individual receives and processes information.

Research on learning style has been going on for decades, attracting a great deal of interest of numerous researchers, coming from different sectors and fields. Each one has given his/her own interpretation on this issue, based on the principles and approaches of his/her field. Consequently, there are many different systems ("models") of classifying learning styles. In this paper, attention has focused on the three most common and widely-used models: Kolb's model, McCarthy's 4MAT model and Dunn and Dunn's model.

Kolb, based on the theories of Piaget, Dewey and Lewin regarding learning experience, built his own model of experiential learning which includes four groups of learners: 1. Accommodators. These students want to try out new experiences, are creative, alternative, flexible and risk takers. This learning style is based on the active experimentation (planning) and concrete experience (doing). 2. Convergers. The learners of this style want to know only what is useful and relevant to themselves. They are good at organizing essential information and they like to set clear goals and specific timelines. They are based on the concrete experience (doing) and abstract conceptualization (thinking) as well as making decisions and solving problems. 3. Assimilators. These learners want to investigate, read, research and learn as much as possible about a topic. They have the patience and the tenacity to delve deeply into the information and they enjoy abstract content. They also believe that they learn from past experiences and from their own results. These learners prefer abstract conceptualization (thinking) and reflective observation (observing). 4. Divergers. These learners value positive and caring environments where their surroundings are comfortable. They like to learn from others through conversation and dialogue and they want to explore and seek alternatives. They tend to be imaginative and altruistic. They are based on concrete experience (doing) and reflective observation (observing).

McCarthy, influenced by Kolb's, set up her own eight-step teaching circle, which uses its learning styles and preferences. She argues that the dominance of the right or left hemisphere of the brain implies different learning styles and preferences in information processing, and that if educator takes advantage of them in planning and organizing his/ her instruction, then its quality will improve. The four types of learning styles that this model supports are: 1. Imaginative Learner. This learner seeks the meaning and asks "Why?" $\mathrm{He} / \mathrm{She}$ is innovative and imaginative and prefers to learn through sensing/watching. He/She wants to know the reason he/she learns something as well as the connection of new knowledge to everyday life. The educator needs to be the motivator. 2. Analytical learner. This learner seeks facts and asks "What?" He/She prefers to learn through watching/thinking as well as creating concepts and models. The educator needs to be the information provider. 3 . Commonsense Learner. This learner seeks the usability and practical application and asks "How does it work?" He/She prefers to learn through thinking/trying out and experimenting. The educator needs to encourage experimentation and be the facilitator/coach.. 4. Dynamic Learner. This learner uses trial and error and asks "What can this become?" He/She takes risks and self-exploration, prefers to learn through trying out/ sensing, but dislikes routines and methodological tasks. The educator needs to let them teach themselves or others and be the resource/evaluator.

Another model that has been created by Dunn and Dunn and it is the most common and widely- used one. It categorizes learners based on how they learn: 1. Auditory learner. These learners absorb spoken and heard material easily and prefer listening to lectures, stories and songs and talking and expressing themselves orally. Therefore, they learn better by listening, whether or not it is to themselves, oral instructions, music and sounds. 2. Visual Learner. These learners learn best from information that they see or read. They like illustrations, pictures and diagrams. Graphic organizers, concept maps and diagrams are very useful tools for them so that they construct meaning visually. In addition color has an impact on their learning. Therefore, they learn through images, videos, diagrams, charts, concept maps or movies. 3. Kinesthetic Learner. These learners learn best through handling materials, doing, writing, and drawing. They want to be involved physically in learning activities that are meaningful and relevant to their lives. They learn through touching, building, creating, physical experience, simulations and role- playing.

\section{E. ICT and Learning Styles}

As mentioned before, educators have a wide variety of methods, strategies and tools that can help them to achieve differentiated instruction. These include new technology and its tools, which allow educators to adapt their instruction to the various learning styles that exist in a classroom. Information and Communication Technology (ICT), thanks to its multimodal character, is suitable for providing educators with choices to respond efficiently to the various learning styles and meet the different needs.

Based on Dunn \& Dunn's model presented previously, specific ICT tools will be proposed for each one type of learning style. Since the Auditory learner learns through listening to sounds, spoken speech and instructions and prefers expressing himself/herself orally, suitable ICT tools 
for him/her are: digital storytelling (platforms like Storybird, Storyboard), Audacity, audio-recordings, screen reader software, speech-to-text software, audiobooks and software like VoiceThread. On the other hand, since Visual learner learns through images, videos, charts, concept maps or movies, some suitable ICT tools for him/her are: digital books, eBooks, digital storytelling, multimedia presentations, virtual field trips, graphic organizers, platforms like Moodle and Weebly, concept map software (like Kidspiration, Bubbl.us), software to create animated videos (such as Powtoon, imovie and animoto). Then, as Kinesthetic learner learns through physical experience, by touching, creating, building and holding, some of the suitable ICT tools for him/her are: Robotics, 3D printing, software such as Google Sketchup, quizlet, blogs, Powtoon and imovies, construction of websites, digital storytelling, the Book Creator platform and online treasure games.

\section{RESULTS AND ANALYSIS}

In the quantitative research, there were 130 participants, of whom $77.7 \%$ are female and $22.3 \%$ male. Regarding the level of education of the participants, the majority (62.3\%) holds a Master Degree while most teach in high school $(33.8 \%)$ and in elementary school (28.5\%). In addition, $73.8 \%$ of the teachers mentioned that in their classroom there are students who come from different cultural backgrounds as well as $64.6 \%$ claimed that there are students whose primary language is not the language in which they teach.

A Pearson product-moment correlation coefficient was computed to assess the relationship between the use of technology in the educators' daily life and its use in their educational practice. There was a positive correlation between the two variables regarding the use of email $(r=6.22$, $N=130, p=0.01)$ and social networks $(r=3.48, n=130$, $N=130, p=0.06$ ). The table below (Table I) summarizes the results.

TABLE I: CORRELATION BETWEEN THE USE OF ICT TOOLS IN EVERYDAY LIFE AND IN EDUCATIONAL PRACTICE

\begin{tabular}{|c|c|c|}
\hline Chi - square test & Pearson Value & Asymp. Sig. (2-sided) \\
\hline Use of email & 6.22 & 0.01 \\
\hline Use of social media & 3.48 & 0.06 \\
\hline
\end{tabular}

TABLE II: DESCRIPTIVE STATISTICS OF THE VIEWS ON THE IMPACT OF

\begin{tabular}{c|c|c|c|c}
\multicolumn{4}{c}{ TECHNOLOGY IN LEARNING BY GENDER } \\
\hline & Gender & Value & Mean & $\begin{array}{c}\text { Std. } \\
\text { Deviation }\end{array}$ \\
\hline $\begin{array}{c}\text { Views on the impact } \\
\text { of technology in } \\
\text { learning }\end{array}$ & Female & 101 & 3.72 & 0.57 \\
\cline { 2 - 5 } & Male & 29 & 3.99 & 0.59 \\
\hline
\end{tabular}

An independent-samples t-test was conducted to compare various factors and educators' views on the impact of ICT tools in the learning process. There was a significant difference in the scores for gender, participation in any training regarding the differentiation using ICT tools and also the subject they teach. More detailed, there was a significant difference in the scores for educators' gender (for females: $M=4.02, S D=0.65$ and for males: $M=3.42, S D=0.64$ ) and their views on the impact of ICT tools in the learning process $[t(42)=2.95, p=0.00]$. The results are summarized below

\section{(Table II).}

Also, a significant difference was found in the scores of their participation in any training regarding the differentiation using ICT tools and their views $[t(42)=2.95, \mathrm{p}=0.00]$. It was found that teachers who have participated in any kind of this training have a more positive attitude towards the impact of technology in the learning process $(M=4.02, S D=0.65)$ than those who have not $(M .=3.42, S D=0.64)$. In addition, a significant difference was found in the scores of the subject taught $[t(128)=2.27, p=0.02]$. Teachers who teach subject relevant to technology (Technology, ICT, Computer Science) were found to have a more positive attitude towards the impact technology in learning $(M=4.04, S D=0.62)$ than those who teach other subjects $(M=3.7, S D=0.56) ;[t(128)=2.27$, $p=0.02]$.

Moreover, measures of central tendency were computed to summarize the data for the three categories of ICT tools for differentiation (by content, by process and by product). The following are the results of this analysis; $N=10, M=22.80$, $S D=8.12$. The results are summarized below (Table III). In more details, measures of dispersion were computed to understand the variability of scores for each one category. The results for the use of ICT for differentiation by content are: $N=10, M=22.80, S D=8.12$, for differentiation by process: $N=10, M=22.80, S D=8.12$ and for differentiation by product: $N=10, M=22.80, S D=8.12$.

TABLE III: DESCRIPTIVE STATISTICS OF THE THREE CATEGORIES OF ICT TOOLS FOR DIFFERENTIATION

\begin{tabular}{c|c|c}
\hline Use of ICT for differentiating learning & Mean & Std. Deviation \\
\hline By content & 3.44 & 0.72 \\
\hline By process & 2.93 & 0.94 \\
\hline By product & 2.72 & 1.11 \\
\hline
\end{tabular}

An independent-sample t-test was conducted to compare various factors that might affect the way they use of ICT tools to differentiate the learning process. Some of these factors were the gender and the grade they teach. There was a significant difference in the scores for females $(M=2.84$, $S D=0.93)$ and males $(M=3.26, S D=0.89) ; \quad t(128)=2.13$, $p=0.03$, showing that male teachers tend to use ICT tools at a greater extent in order to differentiate their instruction by process. The same significant difference was found in the scores for females $(M=2.51, S D=1.01$ and males $(M=3.46$, $S D=1.12),[t(128)=4.3, p<0,001]$ regarding the differentiation by content, supporting again that male teachers use ICT tools at a greater extent to differentiate by this dimension too.

Regarding the differentiation by content, using ICT tools, there was a significant difference in the scores for females $(M=3.26, \quad S D=0.72)$ and males $(M=3.86, \quad S D=0.65)$; $[t(35)=2.37, p=0.02]$ showing that male teachers who teach in Elementary, use ICT tools more in order to differentiate their instruction by this dimension. However, regarding the differentiation by process, female teachers $(M=3.64 S D=0.62)$ who teach in Elementary were found to use ICT tools to differentiate their instruction through this dimension more than male teachers $(M=2.12, S D=0.00) ; \quad[t(22)=3.36$, $p<0.001]$. The results are summarized below (Table IV).

Regarding the differentiation by product, using ICT tools, there was a significant difference in the scores for females $(M=2.16, \quad S D=0.91)$ and males $(M=3.67, \quad S D=0.92)$, 
$[t(22)=4.54, p<0.001]$ showing that male teachers who teach in Elementary use ICT tools in order to differentiate their instruction by this dimension at a greater extent. However, regarding the differentiation by process, female teachers $(M=3.64, S D=0.62)$ who teach in Elementary were found to use ICT tools to differentiate their instruction this dimension more than male teachers $(M=2.12, S D=0.00) ;[t(22)=3.36$, $p<0.001]$. The same applies for teachers who teach in High School since there was a significant difference in the scores for females $(M=2.90, S D=0.94)$ and males $(M=3.78$, $S D=0.97) ;[t(42)=2.84, p<0,001]$. The results are summarized below (Table V).

\begin{tabular}{|c|c|c|c|}
\hline \multicolumn{4}{|c|}{ DIFFERENTIATION BY CONTENT/GRADE } \\
\hline $\begin{array}{c}\text { Use of ICT for } \\
\text { differentiation by content }\end{array}$ & Gender & Mean & Std. Deviation \\
\hline \multirow{2}{*}{ Kindergarten } & Female & 3.64 & 0.62 \\
\hline & Male & 2.12 & 0.00 \\
\hline \multirow{2}{*}{ Elementary School } & Female & 3.26 & 0.72 \\
\hline & Male & 3.86 & 0.65 \\
\hline
\end{tabular}

TABLE V: DESCRIPTIVE STATISTICS OF THE USE OF ICT TOOLS FOR DIFFERENTIATION BY PRODUCT/GRADE

\begin{tabular}{c|c|c|c}
\hline $\begin{array}{c}\text { Use of ICT for differentiation } \\
\text { by product }\end{array}$ & Gender & Mean & Std. Deviation \\
\hline \multirow{2}{*}{ Elementary School } & Female & 2,16 & 0,91 \\
\cline { 2 - 4 } & Male & 3,67 & 0,92 \\
\hline \multirow{2}{*}{ High School } & Female & 2,90 & 0,94 \\
\cline { 2 - 4 } & Male & 3,78 & 0,97 \\
\hline
\end{tabular}

Finally, an independent-sample t-test was conducted to find if certain characteristics of the student population affect the use of ICT tools by teachers who differentiate their instruction. These characteristics were: a) There are students in class with learning difficulties, b) There are students in class with different cultural backgrounds and c) There are students whose mother tongue is not the same with the language of instruction. In more detail, it was found that the teachers who use ICT tools at a greater extent to differentiate their instruction, are those who have students with learning difficulties and are differentiating by process $[t(128)=2.75$, $p<0.001]$ as well as those, who have students coming from different cultural environments and are differentiating by process $[t(128)=2.17, p=0.03]$ and by product $[t(128)=2.22$, $p=0.02]$. Then, greater extent of this use was found when there students whose mother tongue is not the same with the language of instruction when differentiating by process $[t(128)=2.56, p=0.01]$ and by product $[t(128)=2.52, p=0.01]$.

Results from the informative intervention were collected by the comments and impressions of the teachers through a structured discussion. During the screening of the animated video, teachers' reactions were observed and recorded. Almost all of them expressed themselves through non-verbal communication, namely body language, such as body movements, facial expressions and visual communication. Some teachers preferred to keep notes on the materials presented in the animated video and after the screening almost all of them expressed themselves through verbal communication, commenting positively on both the content and the quality of it. During the structured discussion, teachers in general were motivated to a great extent, something that led to a productive exchange of views.
Specific reactions showed the lack of awareness towards the mutual learning model, for which there is less power disparity between students and teachers. Additionally, students are empowered to be more independent and interdependent by taking greater control of their own learning by participating in the planning and implementation of service projects.

It was found that all teachers had met and dealt with the concept of differentiation, but each one for a different reason. Teachers supported that "We are called to differentiate the (learning) process every day", "it was necessary", "differentiation arose mainly during the teaching", "because progress is needed" and "the needs of the students have led to this". They also referred to "mixed group of students" and "the differences in the levels of students' learning".

Moreover, regarding adoption of differentiated instruction, they added that "more work is required by the teacher to take into account the needs of all the students, to learn more about them and to design educational interventions based on them". Also, some of their comments were supported by the relevant literature since they argued that "differentiation is a demanding process, it takes a lot of effort because you have to plan ahead and take different parameters into consideration, such as the needs, the levels, the interests, the personalities; and all of these must have a common point of reference so that all students co-exist in the classroom and follow their programs".

Regarding the results of the adoption of differentiated instruction all the teachers were positive as they claimed that students participated more, learned easier and faster, were more independent and ready to try with greater ease. These comments are consistent with research results of literature reviews regarding the impact of ICT in learning in regard to motivation, self- confidence, independence and active learning. In addition, based on other comments, it might be said that the reaction to something that is different does not refer exclusively to teachers but also students, since both of them ignore the existence of different learning styles and the subsequent relevant differentiated processes.

Regarding suitability of the ICT tools presented, all teachers have described them as suitable, appropriate and realistic since some of them are already in use. More precisely, teachers supported that ICT tools are suitable for each one learning style but this is something that also depends on the school, the system, and its financial capacity. Of course, an important factor is the teacher as some educators want neither to change their instruction by trying something new, nor to use technology. It is, in particular, noteworthy that their comments in this phase confirmed many results of literature review and research studies since they highlighted that ICT is not in itself a differentiation strategy but it is a flexible tool that provides equal opportunities to all students.

Regarding if the teachers have ever used any of the ICT tools presented, all of them gave a positive answer. Namely, they claimed that they have used multimedia presentations (especially in Social Studies, Chemistry and Mathematics) for teaching or presenting new materials, explaining, going deeper into a concept and assessing students. Some teachers supported that they have used digital games in different ways and for different reasons. One such example is the answer "the everyday use of digital games in mathematics calls students to 
solve problems, practicing their skills, improving their critical thinking and strengthening their weak points". Other tools that have been used are: EBooks, audiobooks for students who "prefer to listen rather than read from the textbook", speech -to- text software for students who want to express themselves orally, concept maps for introducing and presenting new concepts and terms (especially in history, physics and chemistry) as well as blogs in order to motivate students to "participate more actively". In addition, the Moodle platform has been used for organizing student population.

Furthermore, almost all the teachers argued that if they were given the opportunity to use some of the ICT tools presented in the animated video, they would choose Powtoon in their instruction in order to motivate students, increase their level of interest and make their lesson more interesting. Many teachers mentioned that although they do not have the appropriate training, they would like to use robotics, blogs and animation in their classrooms. Others argued that to help students who face difficulties in writing or just prefer oral expression, they would choose speech-to-text software.

\section{CONCLUSION}

A In this paper, we analyzed and investigated teachers' views on ICT as a tool for differentiated instruction, the extent to which ICT is used as a tool for the differentiated instruction by teachers, and the ways in which this was achieved.

A first finding is that teachers tend to use the same technology tools they use in their everyday life. They are also well informed in opportunities offered by ICT so that they can differentiate their instruction. Their views on the impact of ICT on the learning process are particularly positive. In terms of gender, male teachers have a more positive attitude towards this impact. The same applies to teachers who have participated in some kind of training on ICT, and the differentiation of instruction. Finally, teachers who teach subjects relevant to technology support that the impact of ICT on the learning process is extremely positive. Gender differences were also observed in the use of ICT to differentiate by process and by content, with a greater use by male teachers in both cases. These kind of differences were also found between the teachers of primary and secondary schools regarding the frequency of ICT use for the differentiation by product with a more frequent use by male teachers again.

It was also found that teachers already use technological tools to differentiate their instruction. Regarding the three dimensions of differentiation, it was noted that they use ICT tools to differentiate their instruction mainly by content, secondly by process and lastly by product. These findings are interesting, as the first two axes of differentiation (by content and by process) are those that require teachers to have the greatest effort and are the most time consuming to design, plan, prepare the material and implement in class. Especially, the last point requires an increased attention and it is significantly more demanding for teachers. This has proven that teachers have the necessary "courage" and they do not waste time, effort to try out new approaches that promise more positive learning outcomes. In regard to the third axis of differentiation, which is related to evaluation of student academic performance, the most limited results confirm the hesitation of each educational system to innovate in the certification of knowledge, concepts that affect the final certificate issued (report, gradebook, baccalaureate) and its rating.

Regarding the frequency of ICT use, the results showed that teachers, who have participated in a ICT-related training relevant to the differentiation using ICT, use it to a greater extent to differentiate the learning process. This is an indication (due to the limited size of the sample) of the importance of teachers' appropriate preparation / training to achieve every educational innovation. Furthermore, it has been found that teachers who have 1) students with learning disabilities, 2) students from different cultural backgrounds, and 3) students whose mother language is not the same as the language of instruction, tend to use ICT tools more to differentiate the learning process, and in particular to differentiate by product.

The results of the qualitative research established that the teachers were well enough informed in the differentiation of the learning process. This, they learned mainly through their teaching, as they have recognized -thanks to their experiencethat this is something necessary to their practice. All of them use ICT tools and we might conclude that they are quite open to new, innovative concepts in education. They also recognize that teachers should provide alternatives to meet the different learning needs of their students. However, they described the practice of differentiation as a difficult and demanding task, but that it also leads to positive learning outcomes. A critical point is that the adoption of differentiated instruction depends on general decisions like class size and composition, assigned teaching work and teachers' training in new pedagogical and teaching methods and approaches.

Regarding the ICT use to differentiate learning process, teachers appear quite open-minded. This is not the case with all teachers for many reasons (age, traditional methods, discomfort). Finally, teachers consider ICT tools suitable for meeting all students' learning needs and styles because of the opportunities they offer, highlighting the importance of the teacher in integrating and using these in the classroom.

In conclusion, the integration and use of ICT tools in education is now a reality. Taking into account the rapid development of technology, modern teachers must create learning environments that meet the needs of all students. A future extension of the results of this research study regarding the concept of differentiated instruction could help to increase the use of ICT in the learning process in the most effective and correct way. In addition, continuous training of the teachers on this concept is paramount in designing educational interventions using ICT, remove learning obstacles, educate all students and meet the learning objectives of the curriculum.

\section{REFERENCES}

[1] M. Koutselini, Differentiating Teaching - Learning in Mixed Ability Classes: Philosophy and Application, Book A. Nicosia, 2006.

[2] C. A. Tomlinson, Deciding to teach them all. Educational Leadership, vol. 61, no. 2, pp. 6-11, 2003. 
[3] C. A. Tomlinson, The Differentiated Classroom: Responding to the Needs of All Learners, Reston, VA: Association for Supervision and Curriculum Development (ASCD), 1999.

[4] C. A. Tomlinson, How to Differentiate Instruction in Mixed-Ability Classrooms (2nd ed.), Reston, VA: Association for Supervision and Curriculum Development (ASCD), 2001.

[5] P. Subban, "Differentiated instruction: A research basis," International Education Journal, vol. 7, no. 7, pp. 935-947, 2006.

[6] N. Waldron and J. Mcleskey, "Helping schools include all learners," Intervention in School \& Clinic, vol. 36, no. 3, pp. 175-181, 2001.

[7] C. A. Tomlinson and A. S. Demirsky, Leadership for Differentiating Schools and Classrooms, Alexandria, VA: Association for Supervision and Curriculum Development (ASCD), 2000.

[8] T. Hall, Differentiated Instruction, Wakefield, MA: National Center on Accessing the General Curriculum, 2002.

[9] G. Erdamar and M. Demirel, "Effects of constructivist learning approach on affective and cognitive learning outcomes," Turkish Educational Sciences, vol. 6, no. 4, pp. 629-661, 2008.

[10] E. B. Susman, "Co-operative learning: A review of factors that increase the effectiveness of computer-based instruction," Journal of Educational Computing Research, vol. 18, no. 4, pp. 303-322, 1998.

[11] S. Harris and A. Kington, Innovative Classroom Practices Using ICT in England, Slough, UK: National Foundation for Educational Research, 2002.

[12] S. Hennessy, "Graphing investigations using portable (palmtop) technology," Journal of Computer Assisted Learning, vol. 16, pp. 243-258, 2000.

[13] S. Rockman et al., A More Complex Picture: Laptop Use and Impact in the Context of Changing Home and School Access: Third Year Study, (2000).

[14] E. M. Comaskey, R. S. Savage, and P. Abrami, "A randomized efficacy study of web-based synthetic and analytic programmes among disadvantaged urban kindergarten children," Journal of Research in Reading, vol. 32, no. 1, pp. 92-108, 2009.

[15] P. S. Klein, O. Nir-Gal, and E. Darom, "The use of computers in kindergarten, with or without adult mediation; effects on children's cognitive performance and behavior," Computers in Human Behavior, vol. 16, no. 6, pp. 591-608, 2000.

[16] P. Subban, "Differentiated instruction: A research basis," International Education Journal, vol. 7, no. 7, pp. 935-947, 2006.

[17] C. A. Tomlinson, The Differentiated Classroom: Responding to the Needs of All Learners, Reston, VA: Association for Supervision and Curriculum Development (ASCD), 1999.

[18] D. Heacox, Differentiated Instruction in the Regular Classroom: How to Reach and Teach All Learners, Grades 3-12, Minneapolis, MN: Free Spirit Publishing, 2002.

[19] C. A. Tomlinson and A. S. Demirsky, Leadership for Differentiating Schools and Classrooms, Alexandria, VA: Association for Supervision and Curriculum Development (ASCD), 2000.

[20] D. H. Clements and B. K. Nastasi, "Electronic media and early childhood education," Handbook of Research on the Education of Young Children, pp. 251-275, New York, NY: Macmillan, 1993.

[21] J. Wright, "A new look at intergrating technology into the curriculum," Early Childhood Education Journal, vol. 26, no. 2, pp. 107-109, 1998.

[22] D. H. Clements and J. Sarama, "Strip mining for gold: Research and policy in educational technology - A response to "Fool's Gold"," AACE Journal, vol. 11, no. 1, pp. 7-69. Norfolk, VA: Association for the Advancement of Computing in Education (AACE), 2003.

[23] H. Eunsook, "A study of 5- to 6- year old children's peer dynamics and dialectical learning in a computer-based technology-rich classroom environment," Computers and Education, vol. 44, no. 1, pp. 69-91, 2005.

[24] K. McCormick and X. Li, "Buried treasure: The impact of computer use on young children's social, cognitive, language development and motivation," AACE Journal, vol. 15, no. 1, pp. 73-79, 2007.

[25] D. Clements and S. Swaminathan, "Technology and school change: New lamps or old?" Childhood Education, vol. 71, no. 5, pp. 275-281, 1995.
[26] S. Harris and A. Kington, Innovative Classroom Practices Using ICT in England, Slough, UK: National Foundation for Educational Research, 2002.

[27] D. Passey, Anytime, Anywhere Learning (AAL) Project Evaluation End of First Year Implementation Summary Report, Lancaster: Lancaster University/AAL, 2000.

[28] S. Rockman et al., "A more complex picture: Laptop use and impact in the context of changing home and school access: Third year study," 2000.

[29] E. M. Comaskey, R. S. Savage, and P. Abrami, "A randomized efficacy study of web-based synthetic and analytic programmes among disadvantaged urban kindergarten children," Journal of Research in Reading, vol. 32, no. 1, pp. 92-108, 2009.

[30] P. S. Klein, O. Nir-Gal, and E. Darom, "The use of computers in kindergarten, with or without adult mediation; effects on children's cognitive performance and behavior," Computers in Human Behavior, vol. 16 , no. 6 , pp. 591-608, 2000.

[31] Software and Information Industry Association. (2000). Research report on the effectiveness of technology in schools (executive summary). [Online]. Available: http://orion2020.org/archivo/educacion/00_7_riete2000.pdf

[32] M. J. Cox, The Effects of Information Technology on Students' Motivation, London, UK: NCET/King's College London, 1997.

[33] H. Becker, "Pedagogical motivations for pupil computer use that lead to student engagement," Educational Technology, vol. 40, no. 5, pp. 5-17, 2000.

[34] D. McConnell, Implementing Computer Supported Cooperative Learning, London, UK: Kogan Page, 2000.

[35] K. Littleton and P. Light, Learning with Computers: Analysing Productive Interactions, London, UK: Routledge, 1999.

[36] S. Roden, "Multimedia: The future of training," Multimedia Solutions, vol. 5, no. 1, pp. 17-19, 1991.

[37] L. Kieler, "Trials in using digital storytelling effectively with the gifted," Gifted Child Today, vol. 33, no. 3, pp. 48-52, 2010.

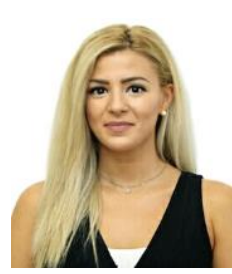

Zoi Karatza was born in Athens (Greece) on February 4th, 1993. Zoi has earned a B.A in early childhood education from the University of Athens (Greece) in 2011 and she has also completed courses in the field of psychology during her studies at the University of Padova (Italy) in 2014. She also earned a M.A. in information and communication technologies in education from the University of Athens, University of Thessaly and Piraeus University of Applied Sciences (Greece) in 2017. Zoi Karatza also attended many training courses and sessions, such as Educational and Psychological Measurements in Special Education (George Washington University) in 2016, Conceptual Math Training for grades K-2 (by Erma Anderson) in 2017, Special Educational Needs (British Council) in 2015 and Supporting children with difficulties in reading and writing (University of London, UCL Institute of Education and Dyslexia International) in 2017.

She is currently working at the American Community Schools (ACS) of Athens (Greece) in the Optimal Learning Program in Elementary School supporting students with learning differences. For the last two years she was working at the same educational institute and department for bot Middle School and Academy and she has also worked as an intern for two-years in public kindergartens, as well as a private tutor, teaching elementary students. In addition, she has published her project titled "Broadening Educational Opportunities for all students: Learning in the Digital Age. What is Gamification? Planning, implementation and evaluation of educational intervention regarding the use of digital games in mathematics" in the proceedings of the 9th ICT Educators' Panhellenic Conference, Spring 2017 and also her action research "Co-Teaching: How to change Teaching \& Learning - The experience of classes with students receiving OLP support" in Ethos Magazine, Fall 2016. 